\title{
Squamous cell carcinoma of the tongue in patients older than 45 years
}

\section{Constantino LEDESMA-MONTES ${ }^{(a)}$ Juan Carlos \\ HERNÁNDEZ-GUERRERO(b) Marco Antonio DURÁN-PADILLA(c) Avissai ALCÁNTARA-VÁZQUEZ ${ }^{(c)}$}

(a) Universidad Nacional Autónoma de México - UNAM, Facultad de Odontología, Laboratory of Clinical Pathology, México City, México.

(b) Universidad Nacional Autónoma de México - UNAM, Facultad de Odontología, Laboratory of Immunology, México City, México.

(c) Hospital General de México "Eduardo Liceaga", Department of Pathology, México City, México.

Declaration of Interests: The authors certify that they have no commercial or associative interest that represents a conflict of interest in connection with the manuscript.

\section{Corresponding Author:}

Constantino Ledesma-Montes

E-mail: cledezma@unam.mx

https://doi.org/10.1590/1807-3107bor-2018.vol32.0123

Submitted: March 01, 2018

Accepted for publication: October 16, 2018

Last revision: October 24, 2018
Abstract: This study aims to evaluate the clinicopathological features, TNM status, AJCC staging and behavior of squamous cell carcinoma of the tongue (SCCT) in patients older than 45 years. The files of the Department of Pathology of the Hospital General de México were reviewed and all cases of SCCT in patients older than 45 years were selected. Clinicopathological features, treatment, follow-up, microscopic diagnosis, and IJCC and TNM staging were retrieved. Complete data from 60 cases were evaluated. They were more common in males (mean age $=63.9$ years). Unexpectedly a high rate of tumors $(38.3 \%)$ were in the base of the tongue (BT). Moderately and poorly differentiated SCCT were the most common. $16.7 \%$ presented lymph node invasion, $15 \%$ were recurrent tumors and BT carcinomas recurred more frequently. A high rate $(81.7 \%)$ were stage II and $48.3 \%$ were low-risk patients. SCCTs in the studied population displayed different clinico-pathological and behavioral features compared with worldwide data. Our results suggest that BT tumors should be treated more aggressively than those in the mobile tongue. BT located tumors were more frequent than previously published. Additional frequency studies will define outcomes in age cohorts with a consensus cut-off for young and elderly populations. More population-based studies should be performed in Latin American regions to acquire accurate data on SCC incidence in elder subpopulations and to identify precisely the etiological factors in these patients.

Keywords: Carcinoma, Squamous Cell; Tongue.

\section{Introduction}

Squamous cell carcinoma (SCC) is the most common oral malignant neoplasm accounting for more than $90 \%$ of oral cancers. ${ }^{1}$ For clinical purposes, the tongue is divided in two parts, the oral portion or mobile tongue (MT) and the base of the tongue (BT), that is anatomically considered part of the oropharynx. The most frequent BTSCC is the HPV-positive type and it is clinically, epidemiologically and microscopically a distinct form of the common head and neck SCC. It is frequently associated to HPV-16, is more common in males and the more commonly associated risk factors are the oral sex and the concomitant HPV infection. ${ }^{2} \mathrm{HPV}$-negative SCC usually affects older patients and the more frequently associated risk factors are alcohol and tobacco. ${ }^{3}$ Both types of SCC have different 
prognosis and it is well known that the HPV-positive type of SCC behaves better than the HPV-negative type. ${ }^{2}$ In contrast MTSCCs are more frequently of the conventional type and the main risk factors are alcohol, tobacco and betel use and abuse. ${ }^{1}$

Some reports showed better outcome in young patients, but others reported it was associated to a significant decrease in the survival rate. $., 5,6$

Frequency of SCCT in Mexico has received little attention and data is scarce ranging its frequency from $22.9 \%$ to $59 \%$ \%,8,10,11,12 and HPV association with oral SCC in Mexican population was not extensively studied. ${ }^{9,10,11}$ In these studies, it was concluded that HPV infection is present in more than $40 \%$ of oral SCC and that HPV-16 infects more than $55 \%$ of these cases. ${ }^{911}$ Interestingly, it was reported that using PCR amplification, HPV infection was $43.5 \% .^{10}$ To date, no detailed study on frequency, clinicopathological features and behavior of SCCT in 45 and older patients has been published.

The aims of the present study were to evaluate the clinicopathological features, TNM status, AJCC staging and behavior of tongue SCC in patients older than 45 years.

\section{Methodology}

A retrospective review of the archives from the Department of Pathology of the Hospital General de Mexico, in Mexico City, from 2001 to 2017 was performed after obtaining Institutional Research and Ethics Board approval. Demographic and clinical data, such as age, gender, location, treatment, microscopic features and degree of differentiation of the selected cases were retrieved. The SCC degree of differentiation was classified in well differentiated (WDSCC), moderately differentiated (MDSCC), poorly differentiated (PDSCC) or carcinoma in situ (CIS). TNM status were according to the WHO guidelines, ${ }^{13}$ and staging of the tumors was done according to the American Joint Committee on Cancer Classification. ${ }^{14}$ Also, data on BT and MT location of the SCCs were analyzed. Student $\mathrm{T}$ test was used and $p<0.05$ was considered statistically significant. The SPSS 13.0 software (IBM, Chicago, Ill) was used for analysis. Data on drinking alcohol, tobacco smoking, treatment and recurrence were also recorded.

\section{Results}

There were 470 cases of intraoral SCC. Of them, 284 were in tongue $(60.4 \%)$ and 60 cases $(21.1 \%)$ of SCC arising in tongue were found (Table 1). They were more common in males than in females $(53.3 \%$ and $46.7 \%$ respectively; $\mathrm{M}: \mathrm{F}$ rate $1.14: 1)$ and this difference was statistically significant $(p<0.03)$. Ages of the patients were between 46 and 82 years with a mean age of 63.9 years ( $\mathrm{SD} \pm 9.8$ years). The degree of differentiation of the analyzed cases varied from poorly to moderately to well-differentiated SCC, and cases of carcinoma in situ (CIS) were also considered. It was a surprise to find that the most common was the MDSCC type (56.7\%), followed by PDSCC (23.3\%) and the less common were both WDSCC and CIS (10\% respectively).

From the 60 analyzed cases, $61.7 \%$ were in the MT and unexpectedly, a high rate of SCCs (38.3\%) were located in BT. This difference was statistically significant $(\mathrm{p}<0.01)$. From these patients, 23 were drinkers (35\%), 27 smoked cigarettes (45\%), 19 patients did both $(31.7 \%)$ and 29 of them were non-drinkers and non-smokers (48.3\%). Our study included 10 cases with lymph node metastasis $(16.7 \%)$ and nine cases $(15 \%)$ presented recurrence from 24 to 120 months after surgical resection (mean= 89 months). Follow-up varied from 8 to 192 months (mean= 51 months). According to data in Table 2 on TNM and AJCC staging most cases were T2 (78.3\%), followed by T4 $(16.7 \%)$. Of them, the most common AJCC stage was stage II ( $81.7 \%)$ and $17 \%$ were in stage IVa. Treatment of the tumors varied from wide excision to hemiglosectomy. From 33 patients treated by wide excision only two of them recurred 36 and 46 months post-treatment. Hemiglosectomy was performed in 17 tumors graded T2 and two of them recurred (24, and 192 months after first excision). All 10 tumors with nodal involvement (16.7\%) were treated with hemiglosectomy and radical neck dissection and of them, five cases $(50 \%)$ were recurrent tumors. All of them were T4 tumors. Interestingly, $66.7 \%$ of the T3, $30 \%$ of the T4, and $2.4 \%$ of the T2 analyzed cases were 
Table 1. Data from patients 45 years and older with SCC of the tongue.

\begin{tabular}{|c|c|c|c|c|c|c|c|c|c|c|}
\hline \multirow{2}{*}{ Age (n) } & \multirow{2}{*}{$\begin{array}{l}\text { Mean age } \\
\text { (years) }\end{array}$} & \multirow{2}{*}{ Males (\%) } & \multirow{2}{*}{ Females (\%) } & \multicolumn{2}{|c|}{ Location } & \multicolumn{4}{|c|}{ Degree of differentiation } & \multirow{2}{*}{$\begin{array}{c}\text { Recurrences } \\
(\%)\end{array}$} \\
\hline & & & & BT (\%) & MT (\%) & WD (\%) & MD (\%) & PD (\%) & CIS (\%) & \\
\hline $46-50(7)$ & 48.1 & $7(11.7)$ & 0 & $3(5)$ & $4(6.7)$ & $1(1.7)$ & $3(5)$ & $1(1.7)$ & $2(3.3)$ & $1(1.7)$ \\
\hline $51-55(4)$ & 54.2 & 0 & $4(6.7)$ & $1(1.7)$ & $3(5)$ & 0 & $2(3.3)$ & $2(3.3)$ & 0 & 0 \\
\hline $56-60(15)$ & 57.9 & $11(18.3)$ & $4(6.7)$ & $4(6.7)$ & 11 (18.3) & $1(1.7)$ & $11(18.3)$ & $1(1.7)$ & 2 (3.3) & 0 \\
\hline $61-65(10)$ & 62.9 & $3(5)$ & $7(11.7)$ & $5(8.3)$ & $5(8.3)$ & 0 & $6(10)$ & $3(5)$ & $1(1.7)$ & $3(5)$ \\
\hline $66-70(7)$ & 68.6 & $7(11.7)$ & 0 & $2(3.3)$ & $5(8.3)$ & $1(1.7)$ & $4(6.7)$ & $2(3.3)$ & 0 & $1(1.7)$ \\
\hline 70-75(8) & 73.6 & 0 & 8 (13.3) & $5(6.7)$ & $3(6.7)$ & $3(5)$ & $5(8.3)$ & 0 & 0 & $2(3.3)$ \\
\hline $76-80(7)$ & 79 & $2(3.3)$ & $5(11.7)$ & $3(5)$ & $4(6.7)$ & 0 & $3(5)$ & $4(6.7)$ & 0 & $1(1.7)$ \\
\hline $80>(2)$ & 82 & $2(3.3)$ & 0 & 0 & $2(3.3)$ & 0 & 0 & $1(1.7)$ & $1(1.7)$ & $1(1.7)$ \\
\hline Total (60) & 63.9 & 32 (53.3) & $28(46.7)$ & 23 (38.3) & $37(61.7)$ & $6(10)$ & $34(56.7)$ & $14(23.3)$ & $6(10)$ & $9(15)$ \\
\hline
\end{tabular}

SCC: Squamous cell carcinoma; WD: Well differentiated; MD: Moderately differentiated; PD: Poorly differentiated; CIS: Carcinoma in situ; BT: Base of the tongue; MT: Mobile tongue.

recurrent tumors and four of the nine recurrences (44.4\%) occurred in low-risk patients (non-drinkers non-smokers). BTSCCs recurred more frequently than MTSCCs (21.7\% and $8.1 \%$ respectively).

$61.7 \%$ of the whole sample were MTs. As it is in Table 3, they were more common in males (67.6\%) than in female patients (32.4\%). This difference was statistically significant $(\mathrm{p}<0.02)$. Age of the patients was between 46 and 82 years with a mean age of 63.6 years. Most of the analyzed MT cases were MDSCCs (59.4\%), followed by PDSCCs (21.6\%) CIS (10.8\%) and WDSCCs $(8.1 \%)$ were the les common type. Most tumors were T2N0M0 (89.2\%). Four were recurrent cases $(10.8 \%)$ at 12,24 and 36 months post resection. Two hemiglosectomies in T4 tumors and two wide resections in one T2 and one T3 neoplasia were performed. 34 cases were stage II and three were stage IV. 31 tumors were treated by wide resection with two recurrences at 12 months, three were treated by hemiglosectomy without recurrence and three recurrent cases with nodal involvement were treated with hemiglosectomy and radical neck dissection. Four of the nine recurrences $(44.4 \%)$ occurred in low-risk patients (non-drinkers non-smokers).

$38.3 \%$ of the whole sample were BTSCCs. Table 4 shows they were more common in females (65.2\%) than in male patients (34.8\%). This difference was statistically significant $(p<0.02)$. Patients were between 48 and 80 years with a mean age of 64.6 years (SD \pm 10.1 years). Most of the analyzed MT cases

Table 2. Status of the analyzed tumors at diagnosis.

\begin{tabular}{|c|c|c|c|c|c|}
\hline System & $\begin{array}{l}\text { Whole } \\
\text { sample }\end{array}$ & Well differentiated & $\begin{array}{l}\text { Moderately } \\
\text { differentiated }\end{array}$ & Poorly differentiated & Carcinoma in situ \\
\hline \multicolumn{6}{|l|}{ TNM } \\
\hline T2NOMO & 47 & 5 & 26 & 13 & 3 \\
\hline T3NOMO & 2 & 0 & 0 & 0 & 2 \\
\hline T3N2bM0 & 1 & 0 & 1 & 0 & 0 \\
\hline T4aNOMO & 3 & 0 & 2 & 0 & 1 \\
\hline $\mathrm{T} 4 \mathrm{dN} 2 \mathrm{bM} 0$ & 7 & 1 & 5 & 1 & 0 \\
\hline \multicolumn{6}{|l|}{ AJCC* } \\
\hline$\|$ & 48 & 5 & 27 & 13 & 3 \\
\hline III & 3 & 0 & 1 & 0 & 2 \\
\hline $\mathrm{IVa}$ & 9 & 1 & 6 & 1 & 1 \\
\hline
\end{tabular}

*American Joint Committee on Cancer Classification. 
Table 3. Data on MTSCC in patients older than 45 years.

\begin{tabular}{lccccccc}
\hline \multirow{2}{*}{ Age $(\mathrm{n})$} & Male $(\%)$ & Female (\%) & \multicolumn{5}{c}{ Degree of differentiation } \\
\cline { 5 - 6 } & & & WD (\%) & MD (\%) & PD (\%) & CIS (\%) & \\
\hline $46-50(4)$ & $4(10.8)$ & 0 & 0 & $2(5.4)$ & 0 & $2(5.4)$ & $1(2.7)$ \\
$51-60(14)$ & $9(24.3)$ & $5(13.5)$ & $1(2.7)$ & $9(24.3)$ & $3(8.1)$ & $1(2.7)$ & 0 \\
$61-70(10)$ & $9(24.3)$ & $1(2.7)$ & 0 & $7(18.9)$ & $3(8.1)$ & 0 & 0 \\
$71-80(7)$ & $1(2.7)$ & $6(16.2)$ & $2(5.4)$ & $4(10.8)$ & $1(2.7)$ & 0 & $2(5.4)$ \\
$81+(2)$ & $2(5.4)$ & 0 & 0 & 0 & $1(2.7)$ & $1(2.7)$ & $1(2.7)$ \\
Total (37) & $25(67.6 \%)$ & $12(32.4 \%)$ & $3(8.1)$ & $22(59.4)$ & $8(21.6)$ & $4(10.8)$ & $4(10.8)$ \\
\hline
\end{tabular}

MTSCC: Mobile tongue squamous cell carcinoma; WD: Well differentiated; MD: Moderately differentiated; PD: Poorly differentiated; CIS: Carcinoma in situ.

were MDSCC (52.2\%), followed by PDSCCs (26.1\%) and $13 \%$ were of the WDSCC type. Most tumors were T2N0M0 (65.2\%), followed by T4dN2bM0 (17.4\%). Five were recurrent cases $(17.4 \%)$ from 24 to 192 months post initial resection and $30.4 \%$ of the patients presented cervical node invasion. 21 hemiglosectomies (seven of them with radical node resection) were made. Most of the cases (65.2\%) were stage II and $26.1 \%$ were stage IVa. Of the high-risk patients, 14 were smokers, 8 were drinkers and smokers and additionally, 39\% were in the low risk group (non-smokers non-drinkers). All recurrences were in smokers.

The WDSCC group was $10 \%$ of the whole sample, there were 3 males and 3 females ( $50 \%$ respectively), with ages were between 49 and 72 years and a mean of 65.7 years ( $\mathrm{SD} \pm 9.7$ years). Three cases were in BT and three were MTSCCs ( $50 \%$ respectively). One case presented node involvement. Three tumors were treated with hemiglosectomy (one with neck dissection) and wide excision was done in three cases ( $50 \%$ respectively). One recurrence was observed. Five (83.3\%) were T2N0M0-stage II tumors and one was a T4dN2bM0-stage IVa neoplasms. Three patients were drinkers and smokers and other three were non-drinkers non-smokers (50\% respectively).

The MDSCC group was the most numerous set of tumors, comprised $56.7 \%$ of the sample and was composed by 17 males and 17 females (50\% respectively). Their ages were between 46 and 79 years (mean $=63.1$ years; $\mathrm{SD} \pm 8.9$ years). Unexpectedly $35.3 \%$ of these SCCs were in BT and MTSCCs were $64.7 \%$. Of the studied neoplasia, $79.4 \%$ were T2NOM0 and $11.8 \%$ were $\mathrm{T} 4 \mathrm{dN} 2 \mathrm{bM} 0.11 .8 \%$ were recurrent tumors (three BTSCCs and one MTSCC), recurring from 12 to 36 months after first resection (mean $=21$ months). $20.6 \%$ of the patients behaved nodal involvement (five BTSCCs and two MTSCCs). This difference was statistically significant ( $p<0.01$ ). $76.5 \%$ of the cases were stage II and $20.6 \%$ were in stage IVa. Of them, $47.1 \%$ were treated by hemiglosectomy and half of them included neck dissection. $52.9 \%$ of the patients were treated by wide surgical excision (all were with MT tumors). Of the high-risk patients ( $\mathrm{n}=16 ; 47.1 \%$ ); 13 were drinkers and 14 were smokers. Of them, 11 were both, drinkers and smokers. Low risk affected patients (non-drinkers non-smokers) were $52.9 \%$.

Table 4. Data on BTSCC in patients older than 45 years.

\begin{tabular}{|c|c|c|c|c|c|c|c|}
\hline \multirow{2}{*}{ Age (n) } & \multirow{2}{*}{ Male (\%) } & \multirow{2}{*}{ Female (\%) } & \multicolumn{4}{|c|}{ Degree of differentiation } & \multirow{2}{*}{ Recurrences $(\%$} \\
\hline & & & WD (\%) & MD (\%) & PD (\%) & CIS (\%) & \\
\hline $46-50(3)$ & $3(13)$ & 0 & $1(4.3)$ & $1(4.3)$ & $1(4.3)$ & 0 & 0 \\
\hline $51-60(5)$ & $2(8.7)$ & $3(13)$ & 0 & $4(17.4)$ & 0 & $1(4.3)$ & 0 \\
\hline $61-70(7)$ & $2(8.7)$ & $5(21.7)$ & $1(4.3)$ & $3(13)$ & $2(8.7)$ & $1(4.3)$ & $4(17.4)$ \\
\hline $71-80(8)$ & $1(4.3)$ & $7(30.4)$ & $1(4.3)$ & $4(17.4)$ & $3(13)$ & 0 & $1(4.3)$ \\
\hline Total (23) & $8(34.8)$ & 15 & $3(13)$ & $12(52.2)$ & $6(26.1)$ & $2(8.7)$ & $5(21.7)$ \\
\hline
\end{tabular}

BTSCC: Base of the tongue squamous cell carcinoma; WD: Well differentiated; MD: Moderately differentiated; PD: Poorly differentiated; $\mathrm{CIS}$ : Carcinoma in situ. 
14 patients composed the PDSCC group (41.2\%), there were 8 males $(57.1 \%)$ and 6 females $(42.9 \%)$. This difference was statistically significant $(\mathrm{p}<0.05)$. Their ages were between 49 and 82 years and the mean age was 67.3 years (SD \pm 11.2 years). As it was in the MDSCCs group, an unexpectedly high rate of patients harbored BTSCCs $(42.8 \%), 57.2 \%$ of the patients showed tumors in the MT and also this difference was statistically significant $(p<0.05)$. Eight tumors were initially treated by wide local excision $(57.1 \%)$ and six hemiglosectomies (42.8\%) were performed (one included submandibular gland excision and radical neck dissection). 13 cases were T2N0M0-stage II and one was T4dN2bM0-stage IVa. Three were recurrent tumors $(21.4 \%)$ recurring all 12 months after initial surgical excision. One tumor presented submandibular gland invasion and nodal involvement 96 months after initial surgical intervention. Five patients were drinkers (55.6\%) seven were smokers, five patients were non-drinkers and non-smokers and three were both, drinkers and smokers. Two recurrent tumors occurred in smokers and one in a non-drinker and non-smoker patient.

There were six examples in the CIS group (17.6\%); 4 males $(66.7 \%)$ and 2 females (33.3\%), with ages between 48 and 82 years (mean age $=59$ years; $\mathrm{SD} \pm 12.6$ years). Location of the tumors was three cases in each MT and BT (50\% respectively). Three tumors were T2N0M0 (stage II), two corresponded to T3N0M0 (stage III) and one was T4aNOMO (stage IVa). 66.7\% of the tumors were initially treated by wide local excision and two hemiglosectomies were performed (one included radical neck dissection). One tumor recurred 12 months after initial surgical excision. Two patients were drinkers (55.6\%), three smokers, two of them were both drinkers and smokers and three patients were non-drinkers and non-smokers. The recurrent tumor occurred in the non-drinker and non-smoker patient.

\section{Discussion}

Tongue cancers are SCCs mainly and they are more frequent in males..$^{15}$ SCCT is a frequent malignant neoplasm presenting variable incidence with geographic and ethnic differences. ${ }^{1}$ Other variables are alcohol and tobacco use and VPH infection. ${ }^{16}$ Interestingly, the age-standardized rates (ASRs) are variable depending on the continent, geographical region, country and local area. ${ }^{17}$

\section{Age}

In several studies, preference for males varied among $48 \%$ and $86.4 \%{ }^{18-23}$ and the male frequency we found $(53.3 \%)$ is within the above-mentioned range. In the literature, mean age is widely variable, it was from 64.3 to 47.5 years, ${ }^{18,21-24}$ and in our study, it was slightly lower (63.9 years).

\section{Microscopic differentiation}

The degree of differentiation of the analyzed cases varied from poorly to moderately to welldifferentiated SCC. It is important to point out that in previous studies, no cases of CIS were included and these data will impact in the final frequency of the studied SCCT and for this reason, our results on the degree of differentiation of the studied malignancies, were different to the previously reported. In other studies, the WDSCC was the most frequent, followed by the MD and the PD types. Differing with previously published data, the most common in our study was the MDSCC type, comprising more than half of the sample $(56.7 \%)$, followed by the PDSCC (23.3\%). Our results are only similar to those from the Ramdass et al. study, ${ }^{21}$ but completely different to those found in other studies showing that the WD type was the most common followed by the moderately differentiated type. ${ }^{18,22,23,24}$ It is interesting to note, that in this study, a high proportion of low risk patients developed SCCT. This data does not agree with previous studies showing that high risk patients comprise the high proportion of the analyzed samples. ${ }^{21,22,23,24,25,26}$ Probably these differences may arise from difficulties in the evaluation of tobacco or alcohol consumption levels. This can occur when clinical histories are reviewed retrospectively.

As it was previously reported, ${ }^{27,28,29,30,31}$ MTSCCs were more frequently found than BTSCC. Compared with previous reports, ${ }^{27,28,29}$ this study revealed a lower proportion of BTSCCs, but other studies showed a similar BTSCC rate. ${ }^{30,31}$ The mean age of 65.7 years 
detected in this study, was similar to previously reported data. $8,9,10,11,12,20,28,32$

\section{TNM Classification}

Compared with previous reports, ${ }^{32,33}$ a high rate of T2 tumors was found (78.3\%) and interestingly, no T1 tumors were detected. $81.7 \%$ of the tumors were AJCC stage II and it is also a high rate compared with previously published studies. ${ }^{28,32,33}$ Our data on nodal involvement (15\%) was the same as that for Chinese population ${ }^{24}$ and low compared with previously reported data. ${ }^{32,33} 15 \%$ of the analyzed SCCTs recurred, this rate was higher to that reported in Chinese patients ${ }^{24}$ and similar to the proportion found in the Mäkitie et al study. ${ }^{33} 88.9 \%$ of the recurrences were in 61 years and older patients and surprisingly, $44.4 \%$ occurred in low-risk patients (non-drinkers non-smokers). These features were not previously reported. BTSCCs recurred more frequently $(21.7 \%)$ than MTSCCs (8.1\%).

In this study, WDSCCs were the less common type of carcinoma and together with the male:female ratio of 1:1 we found, both features were never reported for SCCT. Lymph node involvement and recurrence were low and it can be associated to the fact that $83.3 \%$ were T2-stage II tumors. An unreported feature for this kind of tumors was to find that $50 \%$ of the affected patients were in the low-risk group (non-drinkers non-smokers). This finding suggests that the role of risk factors should be reevaluated in this population.

An unexpected result was that in our study, the MDSCC was the most common of the analyzed tumors $(56.7 \%)$, contrasting with previous data From Finland and India reporting that WDSCC was the most frequent SCCT. ${ }^{20,23} 50 \%$ of the analyzed patients were males with a mean age of 63.1 years and interestingly, $35.3 \%$ of the SCCs were in BT. BT located tumors were more frequent than previously published and as it was stated by Westra et al., ${ }^{2}$ this finding could be related with the increase of HPV infection. $79.4 \%$ were T2-stage II neoplasia, $11.8 \%$ were recurrent tumors and $20.6 \%$ behaved nodal involvement. As it was with WDSCCs, the proportion of low risk affected patients (non-drinkers nonsmokers) was high (52.9\%). Opposed to data from previously reported studies, ${ }^{18,22,23,24} 41.2 \%$ of the sample were PDSCCs and $57.1 \%$ of them were males with a mean age of 67.3 years. As it was detected in the MDSCCs group, an unexpectedly high rate of patients harbored BTSCCs (42.8\%). To our surprise, a high rate of cases was T2-stage II (92.8\%) and 21.4\% were recurrent tumors. As in WDSCCs and MDSCCs, a high proportion of affected patients (55.6\%) were in the low-risk group (non-drinkers and non-smokers). We included in this study clinico-pathological data on six cases of CIS. This kind of tumors never were included in previous SCCT series.

As it was with the whole sample and opposed to data from the literature, ${ }^{27,28,29,30,31}$ most of the analyzed MT cases were MDSCC, followed by PDSCCs and the newly included CIS type. In this study, they were more common in females and mean age was 64.6 years. Additional to published data, we found that $89.2 \%$ of the MT located carcinomas were T2, 92\% were stage II with $10.8 \%$ of recurrent cases and all recurrences appeared in smokers.

Main data obtained analyzing this Mexican population is compared with similar studies in Table $5 .^{26,27,30,34}$ Data in this table shows that frequency, clinical features and behavior complemented with different treatment modalities of the tumors analyzed in this study is different in many aspects compared with SCCT cases from other countries. Data in this table strongly suggests that clinical features and behavior of these tumors in Mexican population should be reviewed to identify precise role of the etiological factors in these patients. Also, our results showed that a high rate of patients with SCCT were low-risk patients (non-drinkers and non-smokers). These results strongly suggest that in Mexican population risk factors should be re-evaluated as causative influences in development of these neoplasms.

\section{Conclusions}

It is important to point out that to date, age categorization of the studied populations used by many authors was very variable and new incidence studies will define outcomes in age cohorts using a consensus cut-off for young and elderly populations.

To date, there are few studies published on this matter and we suggest that more population-based 
Table 5. Comparative data from previous studies in patients older than 45 years with SCCT.

\begin{tabular}{|c|c|c|c|c|c|c|}
\hline \multirow{3}{*}{ Data } & \multicolumn{6}{|c|}{ Authors } \\
\hline & \multicolumn{3}{|c|}{ Mobile tongue } & \multicolumn{3}{|c|}{ Base of the tongue } \\
\hline & Goepfert & Goldstein & This study & Zhen & Krishnatreya & This study \\
\hline$\%$ of sample & NDR & NDR & 61.7 & $4.4 \%$ & 76.1 & 38.3 \\
\hline Mean age & 47.9 yrs & 57.6 yrs & $63.6 \mathrm{yrs}$ & $63.0 \mathrm{yrs}$ & 58.0 yrs & $64.6 \mathrm{yrs}$ \\
\hline Male & $69 \%$ & $59.9 \%$ & $67.6 \%$ & $73.0 \%$ & $79.3 \%$ & $34.8 \%$ \\
\hline Female & $31 \%$ & $40.1 \%$ & $32.4 \%$ & $27.0 \%$ & $20.7 \%$ & $65.2 \%$ \\
\hline \multicolumn{7}{|l|}{ Tumor stage } \\
\hline $\mathrm{T1}$ & $53 \%$ & $48.2 \%$ & $0 \%$ & NDR & NDR & $0 \%$ \\
\hline $\mathrm{T} 2$ & $28 \%$ & $36.0 \%$ & $86.5 \%$ & NDR & NDR & 78.3 \\
\hline T3 & $6 \%$ & $10.7 \%$ & $2.7 \%$ & NDR & NDR & 5.0 \\
\hline $\mathrm{T} 4$ & $5 \%$ & $5.1 \%$ & $10.8 \%$ & NDR & NDR & 16.7 \\
\hline \multicolumn{7}{|l|}{ Nodal stage } \\
\hline NO & $56 \%$ & $56.6 \%$ & $89.2 \%$ & NDR & NDR & $78.3 \%$ \\
\hline N1 & $17 \%$ & $18.4 \%$ & $0 \%$ & NDR & NDR & $0 \%$ \\
\hline N2 & $28 \%$ & $25.2 \%$ & $10.8 \%$ & NDR & NDR & $21.7 \%$ \\
\hline N3 & $0 \%$ & $0 \%$ & $0 \%$ & NDR & NDR & $0 \%$ \\
\hline Metastases & & & & $7.6 \%$ & 3.8 & \\
\hline M1 & $0 \%$ & NDR & $8.1 \%$ & NDR & NDR & $30.4 \%$ \\
\hline M2 & $0 \%$ & NDR & $0 \%$ & NDR & NDR & $0 \%$ \\
\hline M3 & $0 \%$ & NDR & $0 \%$ & NDR & NDR & $0 \%$ \\
\hline \multicolumn{7}{|l|}{ AJCC Stage } \\
\hline I & $39 \%$ & $26.6 \%$ & $0 \%$ & $9.1 \%$ & $1.0 \%$ & $0 \%$ \\
\hline$\|$ & $14 \%$ & $31.7 \%$ & $91.9 \%$ & $12.0 \%$ & $8.2 \%$ & $65.2 \%$ \\
\hline III & $11 \%$ & $26.3 \%$ & $0 \%$ & $21.0 \%$ & $43.4 \%$ & 8.7 \\
\hline IV & $36 \%$ & $15.4 \%$ & $8.1 \%$ & $57.1 \%$ & $47.4 \%$ & $26.1 \%$ \\
\hline \multicolumn{7}{|l|}{ Differentiation } \\
\hline WD & $31 \%$ & $20.3 \% \%$ & $5.0 \%$ & $12.8 \%$ & NDR & $13.0 \%$ \\
\hline MD & $50 \%$ & $70.5 \%$ & $36.7 \%$ & $50.0 \%$ & NDR & $52.2 \%$ \\
\hline PD & $19 \%$ & $9.2 \%$ & $13.3 \%$ & $35.8 \%$ & NDR & $26.1 \%$ \\
\hline $\mathrm{CIS}$ & NDR & NDR & $6.7 \%$ & NDR & NDR & $8.7 \%$ \\
\hline Recurrence & $25 \%$ & 54.5 & 10.8 & NDR & NDR & 21.7 \\
\hline \multicolumn{7}{|l|}{ Treatment } \\
\hline Hemiglosectomy & $22 \%$ & \multirow{2}{*}{$74.1 \%$} & 16.2 & \multirow{2}{*}{$43.8 \%$} & NDR & 91.3 \\
\hline Glossectomy & $8 \%$ & & NDR & & NDR & NDR \\
\hline Neck dissection & $100 \%$ & $75 \%$ & 8.1 & NDR & NDR & 30.4 \\
\hline Smokers & $56 \%$ & $65 \%$ & 35.1 & NDR & NDR & 34.7 \\
\hline Drinkers & $17 \%$ & $59.8 \%$ & 40.5 & NDR & NDR & 60.9 \\
\hline Drinker-smoker & NDR & $25.7 \%$ & 29.7 & NDR & NDR & 34.8 \\
\hline No drinker-smoker & NDR & 74.3 & 54.0 & NDR & NDR & 39.1 \\
\hline
\end{tabular}

SCCT : Squamous cell carcinoma of the tongue; WD: Well differentiated; MD: Moderately differentiated; PD: Poorly differentiated; CIS: Carcinoma in situ; NDR: No data recorded. 
studies should be performed to get accurate data on SCCT incidence in elder subpopulations and to identify precisely the etiological factors in these patients.

Our results suggest that BT tumors should be treated more aggressively than those in the mobile tongue.

BT located tumors were more frequent than previously published and this could be related with increase of HPV infection.

More population-based studies should be performed in Latin American regions to get accurate data on SCC incidence in elder subpopulations and to identify precisely the etiological factors in these patients.

Risk factors in Mexican population should be re-evaluated as causative influences in development of these neoplasms.

\section{Acknowledgments}

The authors like to acknowledge the help of the personnel of the Hospital General de México.

\section{References}

1. Sloan P, Gale N, Hubter K, Lingen M, Nykander K, Riebel J et al. Squamous Cell Carcinoma. In: El-Nagar AK, Chan JKC, Grandis JR, Takata T, Slootweg PJ. WHO Classification of Head and Neck Tumours. $4^{\text {th }}$ ed. IARC, Lyon. 2017. p. 109-11.

2. Westra WH, Boy S, El- Mofty SK, Guillison M, Schwartz MR, Syriänen S, et al. Squamous Cell Carcinoma, HPV-Positive. In: El-Nagar AK, Chan JKC, Grandis JR, Takata T, Slootweg PJ. WHO Classification of Head and Neck Tumours. $4^{\text {th }}$ ed. IARC Press, Lyon. 2017. p. 136-8.

3. Syriänen S, Assand A, El-Mofty SK, Katabi N, Schwartz MR. Squamous Cell Carcinoma, HPV-Negative. In: El-Nagar AK, Chan JKC, Grandis JR, Takata T, Slootweg PJ. WHO Classification of Head and Neck Tumours. 4th ed. IARC Press, Lyon. 2017. p. 138.

4. Annertz K, Anderson H, Biörklund A, Möller T, Kantola $S$, Mork J et al. Incidence and survival of squamous cell carcinoma of the tongue in Scandinavia, with special reference to young adults. Int J Cancer. 2002;101(1):95-9. DOI: 10.1002/ijc.10577

5. Howlader N, Noone AM, Krapcho M, Miller D, Bishop $\mathrm{K}$, Kosary CL et al (eds). SEER Cancer Statistics Review, 1975-2014, National Cancer Institute. Bethesda, MD, https://seer.cancer.gov/csr/1975 2014/, based on November 2016 SEER data submission, posted to the SEER web site, April 2017.

6. Davidson BJ, Root WA, Trock BJ. Age and survival from squamous cell carcinoma of the oral tongue. Head Neck. 2001;23(4):273-9. DOI: 10.1002/hed.1030

7. Zepeda-Nuño JS, Guerrero-Velázquez C, del Toro-Arreola S, Vega-Magaña N, Ángeles-Sánchez J, Haramati J et al. Expression of ADAM10, Fas, FasL and soluble FasL in patients with oral squamous cell carcinoma (OSCC) and their association with clinical-pathological parameters. Pathol. Oncol. Res. 2017;23(2):345-53. DOI: 10.1007/s12253-016-0102-5
8. Hernández-Guerrero JC, Jacinto-Alemán LF, Jiménez-Farfán MD, Macario-Hernández A, Hernández-Flores F, Alcántara-Vázquez A. Prevalence trends of oral squamous cell carcinoma. Mexico City's General Hospital experience. Med Oral Patol Oral Cir Bucal. 2013;18(2):e306-11. DOI: 10.4317/medoral.18043

9. Flores-de la Torre C, Hernández-Hernández DM, Gallegos-Hernández JF. Human papilloma virus in patients with epidermoid head and neck carcinoma: a prognostic factor. Cir Cir. 2010;78(3): 221-8.

10. Anaya-Saavedra G, Ramírez-Amador V, IrigoyenCamacho ME, García-Cuellar CM, Guido-Jiménez M, Méndez-Martínez R et al. High association of human papillomavirus infection with oral cancer: a case-control study. Arch Med Res. 2008;39(2);189-97. DOI: 10.1016/i. arcmed.2007.08.003.

11. González-Ramírez I, Irigoyen-Camacho ME, Ramírez-Amador V, Lizano-Soberón M, Carrillo-García A, García-Carrancá $A$ et al. Association between age and highrisk human papilloma virus in Mexican oral cancer patients. Oral Dis. 2013;19(8):796-804. DOI: 10.1111/odi.12071

12. Luna-Ortiz K, Güemes-Meza A, Villavicencio-Valencia V, Mosqueda-Taylor A. Lip cancer experience in Mexico. An 11 -year retrospective study. Oral Oncol. 2004;40(10):992-9. DOI: 10.1016/j.oraloncology.2004.04.013

13. El-Naggar AK, Chan JKC, Grandis JR, Takata T, Slootweg PJ. WHO Classification of Head and Neck Tumours. $4^{\text {th }}$ edition. IARC. Lyon. 2017.

14. Amin MB, Edge S, Greene F, Byrd DR, Brookland RK, Washington MK et al. Eds. AJCC Cancer Staging Manual. 8th ed. New York: Springer; 2017.

15. Shaikh MH, McMillan NAJ, Johnson NW. HPV-associated head and neck cancers in the Asia Pacific: a critical literature review and meta-analysis. Cancer Epidemiol. 2015;39(6):923-38. DOI: 10.1016/i.canep.2015.09.013 
16. Curado MP, Johnson NW, Kerr AR, Silva NDRS, Hector Lanfranchi $\mathrm{H}$, Pereira DL et al. Oral and oropharynx cancer in South America: Incidence, mortality trends and gaps in public databases as presented to the Global Oral Cancer Forum. Transl Res Oral Oncol. 2016;1:1-7. 2057178X16653761. DOI: 10.1177/2057178X16653761.

17. Nyi Nyi M-P, Gibson TN, Hanchard B, Waugh N, McNaughton D. Trends in incidence and age distribution of oral cavity and oropharyngeal squamous cell carcinomas, Kingston and St Andrew, Jamaica, 1978-2007. West Indian Med J. 2014;63(2):129-33. DOI: 10.7727/wimi.2013.164

18. Loganathan P, Sayan A, Hsu DWK, Paraneetharan S, Ilankovan V. Squamous cell carcinoma of the anterior tongue: is tumour thickness an indicator for cervical metastasis? Int J Oral Maxillofac Surg. 2017;46(4):407-12. DOI: 10.1016/j.ijom.2016.11.003

19. Liao CT, Wen YW, Yang LY, Lee SR, Ng SH, Liu TW et al. Comparative clinical outcomes of Taiwanese patients with resected buccal and tongue squamous cell carcinomas. Oral Oncol. 2017;April 67:95-102. DOI: 10.1016/j.oraloncology.2017.02.011

20. Mroueh R, Haapaniemi A, Grénman R, Laranne J, Pukkila $M$, Almangush $A$ et al. Improved outcomes with oral tongue squamous cell carcinoma in Finland. Head Neck. 2017;39(7):1306-12. DOI: 10.1002/hed.24744

21. Ramdass MJ, Harracksingh A, Maharaj K, Young-Sing Q, Mooteeram J, Barrow S. Incidence of tongue carcinoma in Trinidad and Tobago, West Indies. Oncol Lett. 2015;9(3):1417-9. DOI: 10.3892/ol.2015.2862

22. Sun C, Wang X, Zhong Z, Wang W, Luo J, Chen $X$ et al. Differences in clinicopathological characteristics and prognosis between primary and postirradiation tongue squamous cell carcinoma. J Oral Maxillofac Surg. 2017;75(10):2235-41. DOI: 10.1016/i.joms.2017.02.020

23. Selvamani M, Yamunadevi A, Praveen S, Madhushankari GS. Prevalence of oral squamous cell carcinoma of tongue in and around Davangere, Karnataka, India: A retrospective study over 13 years. J Pharm Bioallied Sci. 2015;7(Suppl 2):491-4. DOI: 10.4103/0975-7406.163511

24. Hakeem AH, Pradhan SA, Kannan R, Tubachi J. Clinical outcome of surgical treatment of T1-2 NO squamous cell carcinoma of oral tongue with observation for the neck: Analysis of 176 cases. Ann Maxillofac Surg. 2016;6(2):235-40. DOI: 10.4103/2231-0746.200331
25. Zhang YY, Wang DC, Su JZ, Jia LF, Peng X, Yu GY. Clinicopathological characteristics and outcomes of squamous cell carcinoma of the tongue in different age groups. Head Neck. 2017;39(11):2276-82. DOI: 10.1002/hed.24898

26. Goepfert RP, Kezirian EJ, Wang SJ. Oral tongue squamous cell carcinoma in young women: a matched comparisondo outcomes justify treatment intensity? ISRN Otolaryngol. 2014;2014, Article ID 529395. doi. 10.1155/2014/529395.

27. Krishnatreya M, Nandy P, Rahman T, Sharma JD, Das A, Kataki $A C$ et al. Characteristics of oral tongue and base of the tongue cancer: a hospital cancer registry based analysis. Asian Pac J Cancer Prev. 2015;16(4):1371-4. DOI: 10.7314/APJCP.2015.16.4.1371

28. Spinato G, Stellin M, Azzarello G, Bonazza D, Zanconati $F$, Politi $D$ et al. Multicenter research into the quality of life of patients with advanced oropharyngeal carcinoma with longterm survival associated with human papilloma virus. Oncol Letters. 2017;14(1):185-93. DOI: 10.3892/ol.2017.6152

29. Thomas GR, Lo K, Nwojo R. Human papillomavirus-induced oropharyngeal cancer in Hispanics in the United States. Laryngoscope. 2017;127(5):1097-101. DOI: 10.1002/lary.26384

30. Zhen W, Karnell LH, Hoffman HT, Funk GF, Buatti JM, Menck HR. The National Cancer Data Base report on squamous cell carcinoma of the base of tongue. Head Neck. 2004;26(8):660-74. DOI: 10.1002/hed.20064

31. Monroe MM, Buchmann LO, Hunt JP, Hitchcock YJ, Lloyd S, Hashibe M. The benefit of adjuvant radiation in surgically-treated T1-2 N1 oropharyngeal squamous cell carcinoma. Laryngoscope Investig Otolaryngol. 2017;2(2):57-62. DOI: 10.1002/lio2.64

32. Sutandyo N, Ramli R, Sari L, Soeis DS. Profile and survival of tongue cancer patients in "Dharmais" Cancer Hospital, Jakarta. Asian Pac J Cancer Prev. 2014;15(5):1971-5. DOI: 10.7314/APJCP.2014.15.5.1971

33. Mäkitie AA, Koivunen $P$, Keski-Säntti $H$, Törnwall J, Pukkila $M$, Laranne J et al. Oral tongue carcinoma and its treatment in Finland. Eur Arch Otorhinolaryngol. 2007;264(3):263-7. DOI: 10.1007/s00405-006-0158-z.

34. Goldstein DP, Bachar GY, Lea J, Shrime MG, Patel RS, Gullane PJ et al. Outcomes of squamous cell cancer of the oral tongue managed at the Princess Margaret Hospital. Head Neck. 2013;35(5):632-41. DOI: 10.1002/hed.23001. 